\title{
The Developmental Context of School Satisfaction: Schools as Psychologically Healthy Environments
}

\author{
Jean A. Baker, Laura J. Dilly, Jana L. Aupperlee, and Sonia A. Patil \\ Michigan State University
}

\begin{abstract}
A positive psychology perspective on school psychology challenges us to think critically about the degree to which schools and schooling processes support children's optimum adjustment. We argue that schools contribute to a student's positive adjustment when they function as psychologically healthy environments for development. In this narrative review, we examine contemporary perspectives on positive adjustment in children and propose a developmental-ecological perspective as one theoretical lens through which to view positive school adjustment. We will critique the empirical literature on contextual factors contributing to school satisfaction, one marker of positive school adjustment. Finally, we will make recommendations for practice and research in this area.
\end{abstract}

Psychology has turned an important corner. Whereas our predominant paradigm has focused on human deficits and pathology (Albee, 2000), we are beginning to recognize positive aspects of well-being as foci for the science and practice of psychology. Positive psychology emphasizes aspects of wellness, or the active quality of adapting to various situations and settings that is exhibited through positive behavioral, psychological, and physiological markers (Cowen, 2000). While a deficits model attempts to remediate problems, a positive psychology orientation proactively encourages an individual's development through building strengths and shaping environments that support adjustment (Seligman \& Csikszentmihalyi, 2000).

Because the contexts in which individuals develop play influential roles in promoting their adaptation and adjustment (Masten \& Coatsworth, 1998), the degree to which schools function as psychologically healthy environments is a

This article was reviewed and accepted for publication under the Editorship of Terry B. Gutkin. Portions of this work were supported by grants R306F60158 and R305T990330 to Randy W. Kamphaus, Jean A. Baker, and Arthur M. Horne from the Institute for At-Risk Children, Office of Educational Research and Improvement, United States Department of Education.

Address correspondence to Jean A. Baker, Ph.D., Department of Educational Psychology, Special Education, and Counseling, Michigan State University, 443A Erickson Hall, East Lansing, MI 48824. E-mail: jbaker@msu.edu. 
key issue within positive psychology as applied to children. Schools are important contexts for children's development because of the time children spend there, the degree to which they influence children's experiences and self-perceptions, and their potential to affect children's life courses. A positive psychology perspective on schooling promotes questions such as, "What educational structures promote adjustment?" or "How does the process of schooling contribute to children's psychological competence?" We will consider several of these issues in this article. We will review contemporary perspectives on positive adjustment in children. Although these literatures provide a background for understanding positive adjustment within school, they lack guiding theories that can be applied readily to school-based practices. We propose a developmental-ecological perspective as one theoretical lens that might guide positive psychology promotion efforts within schools. We will review the empirical literature on contextual factors contributing to positive school adjustment using one marker of positive well-being (i.e., school satisfaction) and organize this literature using the developmental-ecological framework. Finally, we will make recommendations for practice and research in this area.

\section{Contemporary Views of Positive Adjustment in Children}

In the psychological literature, the emphasis on school-aged children's positive development has been housed under the umbrellas of resilience, developmental assets, social-emotional learning, and subjective well-being. Despite differences in terminology and emphases, these literatures consistently find that children who develop well have several variables in common, including sufficient personal assets and competencies, and effective nurturance and support from the social environment. These resources contribute to their positive development and protect them from stress and dysfunction (Luthar, Cicchetti \& Becker, 2000).

Resilience refers to the process of positive adaptation in the face of significant stress or adversity (Luthar et al., 2000). Resilience research focuses on predictable and alterable characteristics, mechanisms, and interactive processes that enable some high-risk students to succeed despite unfavorable circumstances (Doll \& Lyon, 1998). Within the context of schools, this process of positive adjustment is referred to as educational resilience, which Wang, Haertel, and Walberg (1994) define as "the heightened likelihood of success in school and in other aspects of life, despite environmental risks and adversities, brought about by an individual's disposition, conditions, and experiences" (p. 164). Outcome markers of educational resilience include academic, social, autonomous, and planning competencies (Benard, 1991). The study of resilience arose from longitudinal studies of children using a developmental psychology framework (e.g., Masten, 1994; Rutter, 1990). Because of its roots in mainstream psychology, resilience has garnered more empirical study than other child-centered approaches within the positive psychology movement. 
A second approach to understanding positive development is the developmental assets model. Scales and Leffert (1999) describe developmental assets as "positive relationships, opportunities, competencies, values and self-perceptions that children need to succeed" (p. vii). This model identifies 40 assets that fall into the two broad categories of internal resources, such as positive values and social competence, and external resources, including family or community support, that lead to successful outcomes in children. Unlike research in resilience, which focuses on children in high-risk settings, the study of developmental assets encompasses all children. Although the developmental assets movement arose from a religious-affiliated service initiative, the model is now nonsectarian and national in scope and has maintained its primary orientation towards community development to enhance child outcomes. The existing research on the model and its programs' efficacy has been conducted by the program originators (see www.searchinstitute.org for more information). As a community- and service-oriented project, the developmental assets model has not been prominent within the psychology literature but is a popular, national initiative focused on building positive adjustment in children.

Social-emotional learning represents a third strand in the psychological and educational literatures dedicated to fostering positive adjustment in children. Unlike the copyrighted developmental assets model, social-emotional learning represents a loose confederation of scholarship and educational practices centered on promoting children's social and emotional well-being (e.g., Elias et al., 1997). Social-emotional learning has roots in the progressive educational tradition (e.g., Goodlad, 1994) as well as primary prevention and social competence promotion literatures within psychology (e.g., Durlak \& Wells, 1997).

A final approach to understanding children's positive adjustment rests in the subjective well-being literature. Subjective well-being is an individual's experience of the positive qualities of his or her life (Diener, 1984). The construct has three components: positive affect (including emotions such as joy or contentment), negative affect (such as anxiety or despair), and life satisfaction, which is defined as the cognitive appraisal of one's quality of life (see Gilman \& Huebner, this issue). Subjective well-being has its roots in personality psychology and has been applied primarily to adults.

All of these traditions provide a basis for the continued study of children's well-being in school settings but often lack guiding theories that can predict the relationship between school variables and children's positive outcomes. They primarily focus on aspects of the individual rather than on environments that promote adjustment. School-based practice affords opportunities to alter the settings within which children are developing, thereby creating additional avenues for intervention to promote adjustment. Thus, it is important that school-based practices be guided by theory that explicitly accounts for both environmental and individual contributors to positive adjustment. We propose a developmentalecological perspective as one such theory. 


\section{A Developmental-Ecological Perspective on Healthy School Environments}

Schools function as psychologically healthy environments if they meet and appropriately challenge children's developmental needs. The degree of fit between children's developmental needs and capacities and the structures, goals, practices and interactions afforded by the school affects student outcomes. Our beliefs about the linkages between school environments and children's outcomes are shaped by phenomenological and ecological perspectives on development (Bronfenbrenner, 1999, 1979; Deci \& Ryan, 1985; Lazarus, 1991). Within these perspectives, children are seen as agentic contributors to their own development. As they interact with school settings, children construct meaning about themselves, others, and the nature of school. The meanings children derive influence their beliefs about themselves as individuals, as learners, and about the purposes, nature, and goals of education. These beliefs in turn affect children's engagement and participation in school. Within this perspective, schools influence development because their characteristics affect children's appraisals of the school environment which, in turn, affect school-related cognitions and, ultimately, school-related behavior (Baker et al., 2001; Roeser, Eccles, \& Strobel, 1998). For example, practices that extend a sense of classroom community are likely to be appraised as supportive by students, resulting in increased satisfaction and ultimately, increased school engagement (Baker, Terry, Bridger, \& Winsor, 1997). Schools also directly affect development because their structures and practices exert a socializing influence on students. For example, there are meaningful differences in school attitudes and academic outcomes between students in high and low academic "tracks" after controlling for student ability and other distinguishing characteristics (McNeal, 1997). This suggests that this educational practice per se may be associated with differential outcomes for students.

Schools are likely to exert a positive influence if there is a good fit between the developmental needs of students and the affordances of the school environment. Self-determination theory guides our understandings of children's developmental needs. The theory posits that individuals have three fundamental needs: to be meaningfully connected to others, to have developmentally appropriate choice and self-direction, and to perceive themselves as competent in their endeavors (Connell \& Wellborn, 1991; Deci \& Ryan, 1985). Schools that afford opportunities for students to satisfy these needs are likely to be perceived as positive psychological environments. Considerable empirical support suggests that these and other cognitive-motivational processes are associated with student beliefs, attitudes, and learning-related behavior (Eccles, Wigfield, \& Schiefele, 1998). In the followings sections, we will review this literature with an emphasis on school satisfaction, one marker of positive school adjustment.

\section{Contextual Contributors to Positive School Attitudes}

Positive adaptation has been conceptualized in a number of ways including eventual adult competence and productivity (Doll \& Lyon, 1998), the successful 
completion of developmental tasks including the formation of parent-child relationships, and appropriate cognitive development and self-regulation (Masten \& Coatsworth, 1998). Positive school adjustment has been predominantly measured by successful achievement outcomes. However, students' attitudes and beliefs are more proximal outcomes of their interactions with school structures and may be better able to predict eventual school-related behaviors, such as achievement. In our work, we include school satisfaction as one measure of positive school attitudes. School satisfaction is the subjective, cognitive appraisal of the perceived quality of school life. It is grounded in the theoretical work on children's life satisfaction (e.g., Huebner, 1994), one aspect of subjective wellbeing. Typical items measuring the school satisfaction construct include, "I like being in school" and " There are many things about school that I like" (Huebner, 1994). Because it is a subjective construct, school satisfaction accounts for individual differences in students' perceptions of their school experiences. For example, by as early as third grade, differences in school satisfaction distinguish students on mental health, behavioral, and academic indicators of success (Baker, 1998).

School satisfaction can be measured reliably as one attitudinal marker of school adjustment. In this section we will review variables associated with school satisfaction and positive school attitudes. Using ecological systems theory and previous work citing school satisfaction (e.g., Epstein \& McPartland, 1976), we identified both distal environmental variables, such as school climate, classroom practices, school organization, and peer contexts, and more proximal variables, such as academic ability, gender, race, socioeconomic status, mental health, and family contexts, likely to affect school satisfaction. Our model suggests that distal factors interact with more proximal ones to produce positive school outcomes if they adequately support children's developmental needs. For this critique, we selected refereed published articles concerning school satisfaction using computer searches of the psychological literature (PsychInfo) and then cross-referenced their bibliographies. We retained empirical studies that included school satisfaction as an outcome variable or referenced school satisfaction and the contextual variables we had identified. This is a newly emerging area of study, and the literature is sparse; therefore, we also referenced some literatures using other attitudinal indicators of positive school adjustment, such as school affiliation (e.g., Goodenow \& Grady, 1992), school engagement (e.g., Finn, 1989), and academic motivation (e.g., Ames, 1992; Eccles et al., 1998).

School social climate. The empirical study of subjective appraisals of the "quality of school life" can be traced to Epstein and McPartland (1976) who conceptualized school satisfaction as an outcome of schooling rather than as a contributor to academic success. This early work focused on individual difference variables among students and characteristics of schools and generally found low correlations between objective indicators, such as school size, and subjective appraisals of school quality. Contemporary research on school satisfaction attempts to understand the complex processes accounting for student perceptions 
of the quality of school life (e.g., Huebner, Ash, \& Laughlin, 2001). In our current work, we are evaluating the school adjustment of about 900 students across the elementary school period (Baker, Horne, \& Kamphaus, 1999). Our preliminary data suggest that some social climate variables are associated with school satisfaction. For example, the perceived quality of teacher-student relationships from both teacher and child perspectives predicts student school satisfaction (Baker, Davis, Dilly \& Lacey, 2002). Also, classroom environments that are perceived as friendly, supportive, and free of harassment are associated with school satisfaction in this study. The effect sizes were low to moderate across these social climate variables. These findings are consistent with our earlier work in which a sense of the classroom as a psychologically safe environment significantly predicted school satisfaction among urban, impoverished children (Baker, 1998). In that study, the sense of positive classroom climate affected school satisfaction directly and indirectly through its influence on stress and psychological distress. Thus, it appears that a positive social climate acts as an important resource for children's well-being at school. The sense of connectedness to others and support from the social environment are well-established correlates of resilience and contribute to numerous positive outcomes for children (e.g., Masten, 1994)

Classroom structures, goals, and practices. Specific classroom practices are associated with positive school attitudes (Ames, 1992; Eccles et al., 1998). This literature has been developed within educational psychology and has focused primarily on achievement motivation. For example, tasks that provide optimal levels of challenge, feedback that is informational rather than evaluative, recognition of mastery efforts rather than relative performance, and grouping that minimizes interpersonal competition are all associated with enhanced academic motivation (Ames, 1992). Little work has been done in this area specific to school satisfaction. Interestingly, within the literature on job satisfaction, which is the adult correlate of school satisfaction for children, there are strong parallels to this work on classroom-based practices. Workers glean the most satisfaction from jobs that provide variety and autonomy, in which there are clearly identified goals and informational feedback, and with work that they perceive as significant (Argyle, 1987). Of course, there are individual differences in this literature and important distinctions between adult activities and schoolwork. However, the nature of tasks and the manner in which they are presented seem to make an important difference in the attitudinal process. Classroom practices that afford students opportunities to feel competent and to exercise developmentally appropriate autonomy should be associated with positive appraisals of school.

In our current examinations of school satisfaction, we are studying the nature of classroom organization, structure, and tasks. The preliminary data from our longitudinal study suggest that the degree of clarity in classroom rules and predictable structure afforded by the teacher and classroom routines positively affect school satisfaction among elementary school students to a moderate degree (Baker et al., 2002). In our previous work, disciplinary practices were associated 
with school satisfaction, with students expressing poor school satisfaction receiving three times as much punishment as those rating their school satisfaction highly (Baker, 1999). Although these initial studies suggest an association between classroom practices and school satisfaction, much work remains to be done in this area.

Some developmental models of school reform afford an alternate view of the linkages between school practices and positive school attitudes. For example, the Child Development Project (CDP; Battistich, Watson, Solomon, Schaps, \& Solomon, 1991) is an elementary reform model based on intrinsic motivational theory. CDP participation has shown positive effects on children's academic and interpersonal behaviors, attitudes, and motivation. CDP participation changes teachers' classroom behavior, including their warmth and supportiveness, the degree to which they promote cooperation among students, their elicitation of students' critical thinking and problem solving, an emphasis on prosocial values, and a low use of extrinsic behavior control. This in turn influences students' classroom behavior, as measured by academic engagement and positive interpersonal behavior. The student behavior leads to perceptions of a sense of school community, which in turn leads to positive school-related outcomes, including enjoyment of class, increased learning motivation, concern for others, and conflict resolution skills (Battistich, Schaps, Watson, \& Solomon, 1996). Thus, classroom practices that permit students to experience a sense of connectedness, competence, and contribution may be important foci for further study of positive school attitudes.

School organization. Larger aspects of school organization and structure, such as how schools organize time, curriculum, spacing, and the continuity of contact between teachers and students affect achievement outcomes (Baker et al., 2001). Within this literature, some attention has been paid to attitudinal indicators of adjustment. For example, schools that keep students and teachers in persistent cohorts across time are associated with increased positive attitudes toward schooling (e.g., Felner et al., 1993). This is an example of a school organizational practice that promotes students' sense of connectedness to others and enhances the predictability of the school environment. From a developmentalecological perspective, this type of school reorganization should be associated with increased school satisfaction. However, little work has been done specifically relative to school attitudinal outcomes.

Peer contexts. Children's peers play an influential role in their positive development and wellness. Children's friendships serve as an important context for students' comfort and support (Doll, 1996). Peer groups also serve to socialize children, causing children to adopt similar goals and attitudes as their peers. For example, elementary students self-select into peer groups with similar motivational orientations to their own (Kindermann, 1993). Inclusion in a peer group with positive orientations and motivations can be an important factor in a student's positive adjustment in school. Wentzel (1994) found that children who felt their peers supported them adopted prosocial and socially responsible goals 
within the classroom, such as aiding classmates in classroom activities. In contrast, socially rejected adolescents who are actively disliked by many peers perceive less social support within the classroom and exhibit less positive psychosocial, behavioral, and scholastic outcomes (East, Hess, \& Lerner, 1987).

Some empirical evidence suggests a link between peer relationships and school satisfaction. Ash and Huebner (1998) found a significant correlation between the school satisfaction factor and the friend satisfaction factors of the Multidimensional Students' Life Satisfaction Scale (MSLSS; Heubner, 1994) for a group of nongifted students $(r=.32, p<.05)$. Children who had more friends and higher quality friendships scored higher on measures of life satisfaction (Huebner \& Alderman, 1993), possibly because an increase in friendship provides more opportunities for social support. Students' peer groups also influence their school satisfaction. Students whose peers have positive attitudes toward school have more positive attitudes toward school themselves (Epstein, 1981). Also, Ladd, Kockenderfer, and Coleman (1996) reported that students, particularly boys, who were in conflict with their peers had lower levels of school liking. As in the classroom climate area, social contexts that are characterized by positive attributes and lack negative ones are associated with increased school satisfaction. From a developmental ecological perspective, positive peer relationships provide an avenue to meet students' developmental needs for connectedness to others, thus enhancing their positive adjustment at school.

In the following sections, we review a number of individual difference variables associated with school satisfaction in the literature. Overall, the findings suggest small associations between personal characteristics and our positive attitudinal indictor. However, from a developmental ecological perspective, they are important to consider as they represent some of the individual differences with which children interact with the school environment.

Student demographic variables. The relation between student gender, race, and socioeconomic status and school satisfaction has been examined in several studies. There are conflicting findings in the literature, but the overall effect of demographic characteristics on school satisfaction is small. For example, Okun, Braver, and Weir (1990) found that girls reported significantly higher school satisfaction scores than boys but noted that the gender difference was small (etasquare $=.016$ ). Huebner and his colleagues $(2001)$ found no variation by gender. Studies that found differences in school satisfaction by race (eta-square $=.097$; Okun et al., 1990) and those that did not (Huebner et al., 2001) are likely attributable to measurement and sampling differences between the studies. These conflicting results reflect the difficulty of using objective indicators, such as race or gender, to predict subjective experiences. From a developmental-ecological perspective on positive school adjustment, it may be more beneficial to examine how race or gender interact with specific school practices to influence developmental outcomes. For example, studying the interaction between race and culturally responsive teaching practices, which explicitly acknowledge the strength 
and vitality of cultural diversity and empower students from minority cultures (Gay, 2000), and school satisfaction may afford a more sensitive assessment than that between race and school satisfaction alone.

Student academic ability. Students' subjective appraisals of their lives do not appear to be closely related to their academic performance and intellectual abilities. Epstein and McPartland (1976) reported that "high grades alone are not enough to make school experiences satisfying" (p. 20), noting that the opportunity to participate may be more important than a student's achievement scores. More recently, Huebner (1991) found that children's global life satisfaction was not significantly correlated with their recent school grades $(r=-.12, p=.14)$. Further, a measure of global life satisfaction was unable to differentiate between a group of normally achieving elementary students and groups of students who were at risk for academic failure due to learning and/or emotional problems (Huebner \& Alderman, 1993). Ash and Huebner (1998) found that gifted and nongifted students do not differ in their levels of global life satisfaction. However, gifted students' reports of their school satisfaction contributed to a greater portion of their global life satisfaction than the school satisfaction of nongifted students. Consistent with the literature presented in the previous classroom practices section, it may be more fruitful to study the connections between classroom practices that afford students with opportunities to perceive themselves as active, successful participants in their own learning than to study gross indicators of ability. Practices that afford developmentally appropriate opportunities to master curriculum are associated with positive attitudes toward school, as predicted from a developmental ecological framework.

Student mental health. Studies examining antecedents and determinants of school satisfaction have also explored mental health variables such as self-esteem, depression, and stress. Since scant school satisfaction literature exists, examining mental health variables associated with life satisfaction is useful. Previous studies suggested an association between life satisfaction and self-esteem (Huebner \& Alderman, 1993), locus of control (Huebner et al., 2001), extraversion versus neuroticism (Huebner et al., 2001), depression and loneliness, externalizing and internalizing behavior problems (Huebner \& Alderman, 1993), and life satisfaction. The findings suggest the importance of considering the role psychological variables play in children's overall life satisfaction.

Within the school satisfaction literature the relationship with self-esteem has been conflicting. Early in the study of school satisfaction, Epstein and McPartland (1976) reported that a small though statistically significant relation existed between self-esteem and school satisfaction $(r=.15)$, and that anxiety about school was moderately negatively correlated with school satisfaction $(r=-.43)$. Huebner and McCullough (2000) found that high SES, Caucasian students with higher academic self-efficacy indicated higher levels of school satisfaction $(r=$ $.28, p<.01)$. However, Baker (1998) found a negative relationship $(r=-0.17$, $p<.05)$ between academic self-concept and school satisfaction among urban, low-income, African American students. Evidence suggests that the relationship 
between self-esteem and school satisfaction might vary for different groups of students (Huebner et al., 2001).

Research also suggests interrelationships between psychological and environmental variables that influence school satisfaction (Baker, 1998; Huebner et al., 2001). For instance, Baker (1998) found that school climate had a significant indirect effect on school satisfaction by influencing psychological variables such as psychological distress and self-concept. More recently, internal locus of control mediated the relationship between negative life experiences and school satisfaction, indicating the contribution of both psychological and environmental variables to school satisfaction reports (Huebner et at., 2001). The interplay of these variables implies the necessity of optimizing many aspects of children's lives in order to promote their quality of school life. It also suggests the importance of considering school satisfaction, and other indices of well-being, using multivariate models that account for the subtle interactions of students and their environments.

Family contexts. Although families are not immediately proximal to the school setting, we reviewed their associations with school satisfaction because their influence is so pervasive on children's development. For example, the quality of the home environment predicts significant positive changes in children's overall adjustment ( $r=.11, p<.10$; Dubow \& Ippolito, 1994), and predicts increased positive expectations for the future $(r=.49, p<.01$; Dubow, Arnett, Smith, \& Ippolito, 2001). Specifically, families influence positive school attitudes in many ways including modeling academically oriented behaviors (such as literacy activities), socializing an achievement orientation and values regarding education, and direct teaching and structuring of the home so that school tasks are emphasized and accommodated (Scott-Jones, 1995). The active involvement of home with schools provides continuity across these two critical developmental settings and extends opportunities for learning activities outside of school (Christenson \& Godber, 2001).

Recent studies have demonstrated that families are an important contributor to school satisfaction. Baker (1998) demonstrated that quality of family life had an effect on school satisfaction $(r=.20, p<.05)$, and that it was negatively correlated with child-reported psychological distress $(r=-.35, p<.001)$. In addition, positive daily events, including family and peer interactions, moderately predicted school satisfaction $(r=.24, p<.05$, Huebner \& McCullough, 2000). In addition, family and parental satisfaction were among the strongest predictors of global life satisfaction (Terry \& Huebner, 1995; Huebner, 1991). In short, families act as important environmental influences and resources for the development of positive school attitudes.

\section{Summary}

In sum, the growing body of research on school satisfaction has examined a number of environmental characteristics such as school climate and practices, 
as well as person-centered correlates such as ability and mental health. The field lacks comprehensive models that account for these distal and proximal variables within school settings. However, using a developmental-ecological framework, we can organize the existing literature to suggest school practices that are associated with increased school satisfaction. School practices that (1) enhance children's meaningful connections to others in the school environment (through positive teacher-student relationships, successful peer relationships, and a positive social climate), (2) enhance children's sense of competence as learners (through educational practices that promote self-regulated learning), and (3) promote a sense of autonomy and self-direction (such as a mastery orientation toward tasks and informational feedback) are associated with positive school attitudes.

The degree of continuity and support from other important developmental resources, such as families, is also critical to the development of positive school adjustment. Of course, student attitudinal indicators concerning school are affected by a variety of factors and individual difference variables. For example, student expectancy for success affects how students interpret teacher praise or criticism (Pintrich \& Blumenfeld, 1985). Thus, any conclusions regarding specific school structures and school satisfaction should be made cautiously. However, conceptualizing the school as a psychologically healthy environment according to its capacity to meet children's developmental needs effectively might afford fresh perspectives on school psychology practice and research.

\section{IMPLICATIONS FOR PRACTICE AND RESEARCH}

An orientation toward positive psychology has significant implications for school psychology practice and research. This perspective challenges us to consider markers of positive adjustment rather than diagnoses of developmental problems and to engage in preventative rather than reactive models of practice. There is a growing commitment within psychology (e.g., Durlak \& Wells, 1997), including school psychology (e.g., Minke \& Bear, 2000), to prevention as an important model of service delivery. Considering not just the prevention of dysfunction but the promotion of adjustment is a critical feature of a positive psychology approach to school-based practice.

The promotion of children's wellness should have several foci within school psychology practice. Individual children and families can benefit from skills enhancement programs to build competencies and promote adjustment. This framework is consistent with the prevalent mental health perspective in schools, and empirically supported models exist to guide our practice in this area. However, we believe that school psychologists have an important role in reframing educational practice so that schools provide optimum developmental supports for students. Our roles as organizational consultants and our knowledge from educational psychology can be beneficial in school or classroom reform initiatives. 
Examples of such initiatives include the practice of looping, which maintains class assignments and keeps students together with a teacher across multiple years, can enhance student-teacher interactions. Further, "school within a school" strategies that subdivide teacher and student populations into smaller teams or pods can create more personal communities for both students and teachers. We can encourage schools to consider the degree to which recommended practices afford students opportunities to enhance their sense of connectedness to others, enhance their sense of competence, or provide opportunities for developmentally appropriate self-direction. The degree to which our schools function as psychologically healthy environments should be central to the discourse on reform within schools.

However, many important questions regarding the effects of school environments on children's well-being remain unanswered. Further research is needed to systematically identify aspects of schooling that contribute to school satisfaction and other attitudinal indicators of school adjustment. As mentioned earlier, the literature on job satisfaction (e.g., Argyle, 1987) is more fully developed and could provide a model for studying features of schools that contribute to satisfaction. For example, aspects of work that promote intrinsic motivation (such as autonomy, significance, etc.) may apply directly to the educational practice literature. The robust finding that interpersonal relations contribute highly to job satisfaction buttresses our emphasis on the social climate of schools. Although there are important distinctions between adult workers and students, this literature may provide some structure for future work in school satisfaction.

Similarly, cognitive-motivational processes are complex and highly individualized (Lazarus, 1991). There are conflicting data within the school satisfaction literature regarding individual difference variables, such as race and gender. This points to the difficulty of using objective indicators to understand students' subjective experiences. It also suggests the need to test more complex, theoretically driven models of student attitudinal outcomes. Research in some areas of positive psychology is atheoretical and not designed to test potentially powerful moderating or mediating influences on adjustment (Luthar et al., 2000). Important work is being done in this area (e.g., Huebner et al., 2001); however, much more is needed.

This type of research is further complicated when studying the influence of environmental features. Environments are complex, multifaceted entities that create numerous theoretical and pragmatic difficulties for research (Wachs, 1992). Careful conceptual and methodological consideration is needed when attempting to understand the potentially reciprocal, hierarchical, and embedded nature of relationships between children and school environments.

Despite these concerns, we believe that school psychologists have an important place at the table of positive psychology. Our perspectives that development is transactional and that environments play key roles in shaping or constraining development are important as theory unfolds in this area. Our 
sensitivity to the effects of schools on children's development encourages us to look critically and creatively at environmental contributors to children's positive adjustment.

\section{REFERENCES}

Ames, C. (1992). Classrooms: Goals, structures, and student motivation. Journal of Educational Psychology, 84, 261-271.

Albee, G. W. (2000). The Boulder Model's fatal flaw. American Psychologist, 55, 247-248.

Argyle, M. (1987). The psychology of happiness. London: Methuen.

Ash, C. \& Huebner, E. S. (1998). Life satisfaction reports of gifted middle-school children. School Psychology Quarterly, 13, 310-321.

Baker, J. A. (1998). The social context of school satisfaction among urban, low-income, AfricanAmerican students. School Psychology Quarterly, 13, 25-44.

Baker, J. A. (1999). Teacher-student interaction in urban "at-risk" classrooms: Differential behavior, relationship quality, and student satisfaction with school, Journal of Elementary Education, 100, 57-70.

Baker, J. A., Davis, S. M., Dilly, L. J., \& Lacey, C. (2002). Promoting resilience and competence with at-risk students: Prevention strategies that work. Paper presented at the annual meeting of the National Association of School Psychologists, Chicago.

Baker, J. A., Derrer, R., Davis, S., Dinklage-Travis, H., Linder, D., \& Nicholson, M. (2001). The flip side of the coin: Understanding the school's contribution to drop-out. School Psychology Quarterly, 16, 406-427.

Baker, J. A., Horne, A., \& Kamphaus, R. W. (1999). Project A. C. T. Early: Addressing the context of teaching for young students at-risk. Grant no. R305T990330, Institute for At-Risk Children, Office of Educational Research and Improvement, United States Department of Education: Washington, DC.

Baker, J. A., Terry, T., Bridger, R., \& Winsor, A. (1997). Schools as caring communities: A relational approach to school reform. School Psychology Review, 26, 586-602.

Battistich, V., Schaps, E., Watson, M., \& Solomon, D. (1996). Prevention effects of the Child Development Project: Early findings from an ongoing multisite demonstration trial. Journal of Adolescent Research, 11, 12-35.

Battistich, V., Watson, M., Solomon, D., Schaps, E., \& Solomon, J. (1991). The Child Development Project: A comprehensive program for the development of prosocial character. In W. M. Durtines \& J. L. Gewirtz (Eds.), Handbook of moral behavior and development: Vol. 3: Application (pp 1-34). New York: Lawrence Erlbaum.

Benard, B. (1991). Fostering resiliency in kids: Protective factors in the family, school, and community. Portland, OR: Northwest Regional Educational Laboratory.

Bronfenbrenner, U. (1979). The ecology of human development. Cambridge, MA: Harvard University Press.

Bronfenbrenner, U. (1999). Environment in developmental perspective: Theoretical and operational models. In S. L. Friedman \& T. D. Wachs (Eds.), Measuring environments across the life span: Emerging methods and concepts (pp. 3-31). Washington, DC: American Psychological Association.

Christenson, S. L., \& Godber, Y. (2001). Enhancing constructive family-school connections. In J. N. Hughes \& A. M. La Greca (Eds.), Handbook of psychological services for children and adolescents. (pp. 455-476). New York: Oxford University Press.

Connell, J. P., \& Wellborn, J. G. (1991). Competence, autonomy and relatedness: A motivational analysis of self-system processes. In M. Gunnar \& L. A. Sroufe (Eds.), Minnesota Symposium of Child Psychology (Vol. 22, pp. 43-77). Minneapolis: University of Minnesota Press.

Cowen, E. L. (2000). Now that we all know that primary prevention in mental health is great, what is it? Journal of Community Psychology, 28, 5-16. 
Deci, E. L., \& Ryan, R. M. (1985). Intrinsic motivation and self-determination in human behavior. New York: Plenum.

Diener, E. (1984). Subjective well-being. Psychological Bulletin, 95, 542-575.

Doll, B. (1996). Children without friends: Implications for practice and policy. School Psychology Review, 25, 165-183.

Doll, B., \& Lyon, M. A. (1998). Risk and resilience: Implications for the delivery of educational and mental health services in schools. School Psychology Review, 27, 348-363.

Dubow, E. F., Arnett, M., Smith, K., \& Ippolito, M. (2001). Predictors of future expectations of inner-city children: A 9-month prospective study. Journal of Early Adolescence, 21, 5-28.

Dubow, E. F. \& Ippolito, M. F. (1994). Effects of poverty and quality of the home environment on changes in the academic and behavioral adjustment of elementary school-age children. Journal of Clinical Child Psychology, 23, 401-412.

Durlak, J. A., \& Wells, A. M. (1997). Primary prevention mental health programs for children and adolescents: A meta-analytic review. American Journal of Community Psychology, 25, $115-152$.

East, P., Hess, L., \& Lerner, R. (1987). Peer social support and adjustment of early adolescent peer groups. Journal of Early Adolescence, 7, 153-163.

Eccles, J. S., Wigfield, A., \& Schiefele, U. (1998). Motivation to succeed. In W. Damon (Series Ed.), \& N. Eisenberg (Vol. Ed.), Handbook of child psychology: Vol. 3: Social, emotional, and personality development (5th ed.; pp. 1017-1095). New York: Wiley.

Elias, M. J., Zins, J. E., Weissberg, R. P., Frey, K. S., Greenberg, M. T., Haynes, N. M., Kessler, R., Schwab-Stone, M. E., \& Shriver . P. (1997). Promoting social and emotional learning: Guidelines for educators. Alexandria, VA: ASCD

Epstein, J. L. (1981). The quality of school life. Lexington, MA: Lexington Books.

Epstein, J. L., \& McPartland, J. M. (1976). The concept and measurement of the quality of school life. American Educational Research Journal, 13, 15-30.

Felner, R. D., Brand, S., Adan, A. M., Mulhall, P. F., Flowers, N., Sartain, B., \& DuBois, D. L. (1993). Restructuring the ecology of the school as an approach to prevention during school transitions: Longitudinal follow-ups and extensions of the School Transitional Environment Project (STEP). Prevention in Human Services, 10, 103-136.

Finn, J. D. (1989). Withdrawing from school. Review of Educational Research, 59, 117-124.

Gay, G. (2000). Culturally responsive teaching: Theory, research, \& practice. New York: Teachers College Press.

Gilman, R., \& Huebner, S. (2003). A review of life satisfaction research with children and adolescents. School Psychology Quarterly, 18, 192-205.

Goodenow, C., \& Grady, K. E. (1992). The relationship of school belonging and friends' values to academic motivation among urban adolescent students. Journal of Experimental Education, $62,60-71$.

Goodlad, J. I. (1994). What schools are for (2nd ed.). Bloomington, IN: Phi Delta Kappa Educational Foundation.

Huebner, E. S. (1991). Correlates of life satisfaction in children. School Psychology Quarterly, 6, 103-111.

Huebner, E. S. (1994). Preliminary development and validation of a multidimensional life satisfaction scale for children. Psychological Assessment, 6, 149-158.

Huebner, E. S., \& Alderman, G. L. (1993). Convergent and discriminant validation of a children's life satisfaction scale: Its relationship to self- and teacher-reported psychological problems and school functioning. Social Indicators Research, 30, 71-82.

Huebner, E. S., Ash, C., \& Laughlin, J. E. (2001). Life experiences, locus of control, and school satisfaction in adolescence. Social Indicators Research, 55, 167-183.

Huebner, E. S., \& McCullough, G. (2000). Correlates of school satisfaction among adolescents. Journal of Educational Research, 93, 331-335.

Kindermann, T. A. (1993). Natural peer groups as contexts for individual development: The case of children's motivation in school. Developmental Psychology, 29, 970-977. 
Ladd, G. W., Kochenderfer, B. J., \& Coleman, C. C. (1996). Friendship quality as a predictor of young children's early school adjustment. Child Development, 67, 1103-1118.

Lazarus, R. S. (1991). Progress on a cognitive-motivational-relational theory of emotion. American Psychologist, 46, 819-834.

Luthar, S. S., Cicchetti, D., \& Becker, B. (2000). The construct of resilience: A critical evaluation and guidelines for future work. Child Development, 71, 543-562.

Masten, A. S. (1994). Resilience in individual development: Successful adaptation despite risk and adversity. In M. C. Wang \& E. W. Gordon (Eds.), Educational resilience in inner city America: Challenges and prospects (pp. 3-23). Hillsdale, NJ: Erlbaum.

Masten, A. S., \& Coatsworth, J. D. (1998). The development of competence in favorable and unfavorable environments: Lessons from research on successful children. American Psychologist, 53, 205-220.

McNeal, R. B. (1997). High school dropouts: A closer examination of school effects. Social Science Quarterly, 78, 209-222.

Minke, E. M., \& Bear, G. G. (2000). Preventing school problems-promoting school success: strategies and programs that work. Bethesda, MD: National Association of School Psychologists.

Okun, M. A., Braver, M. W., \& Weir, R. M. (1990). Grade level differences in school satisfaction. Social Indicators Research, 22, 419-427.

Pintrich, P. R., \& Blumenfeld, P. C. (1985). Classroom experience and children's self-perceptions of ability, effort, and conduct. Journal of Educational Psychology, 77, 646-57.

Roeser, R. W., Eccles, J. S., \& Strobel, K. R. (1998). Linking the study of schooling and mental health: Selected issues and empirical illustrations at the level of the individual. Educational Psychologist, 33, 129-133.

Rutter, M. (1990). Psychosocial resilience and protective mechanisms. In J. Rolf, A. S. Masten, D. Cicchetti, K. H. Nuechterlein, \& S. Weintaub (Eds.), Risk and protective factors in the development of psychopathology (pp. 181-214). New York: Cambridge University Press.

Scales, P. C., \& Leffert, N. (1999). Developmental assets: A synthesis of the scientific research on adolescent development. Minneapolis: The Search Institute.

Scott-Jones, D. (1995). Parent-child interactions and school achievement. In B. A. Ryan, G. R. Adams, T. P. Gullotta, R. P. Weissberg, \& R. L. Hampton (Eds.), The family-school connection (pp. 75-107). Thousand Oaks, CA: Sage.

Seligman, M., \& Csikszentmihalyi, M (2000). Positive psychology: An introduction. American Psychologist, 55, 5-14.

Terry, T., \& Huebner, E. S. (1995). The relationship between self-concept and life satisfaction in children. Social Indicators Research, 35, 39-52.

Wachs, T. D. (1992). The nature of nurture. Newbury Park, CA: Sage.

Wang, M. C., Haertel, G. D., \& Walberg, H. J. (1994). Educational resilience in inner cities. In M. C. Wang \& E. W. Gordon (Eds.), Educational resilience in inner-city America: Challenges and prospects (pp. 45-72). Hillsdale, NJ: Erlbaum.

Wentzel, K. R. (1994). Relations of social goal pursuit to social acceptance, classroom behavior, and perceived social support. Journal of Educational Psychology, 86, 173-182.

Action Editor: Richard Gilman

Acceptance Date: September 3, 2002

Jean A. Baker, Ph.D., is Associate Professor and Co-Director of the School Psychology Program at Michigan State University. Her research interests center on the mechanisms within classrooms and school environments that promote children's positive mental health and adjustment. Dr. Baker is President-Elect of the Division of School Psychology of the APA. The School Psychology Program at Michigan State University is accredited by the APA. 
Laura Dilly is a doctoral student in school psychology at Michigan State University. Her research interests include indicators of positive student adjustment, the social-emotional context of classrooms, and resilience. She received her bachelor's degree in psychology from Vanderbilt University.

Jana Aupperlee, B.A., is a graduate student in school psychology at Michigan State University. Her research interests include parental involvement in education and school satisfaction. She received her B.A. from Calvin College in Grand Rapids, MI.

Sonia Patil, B.A., is currently in the School Psychology Doctoral Program at Michigan State University. Her research interests include the relationship between social support and school satisfaction. She received her B.A. in psychology from the University of Virginia. 